\title{
Systemic evening primrose oil improves the biophysical skin parameters of healthy adults
}

\author{
R. Muggli \\ AdviServ Consulting, Rotbergstrasse 11, CH-4114 Hofstetten, Switzerland
}

Received 20 December 2004, Accepted 23 April 2005

Keywords: biomechanical skin parameters, cosmeceutical, evening primrose oil, gamma-linolenic acid

\section{Synopsis}

Biophysical skin parameters are indicators of agerelated structural and functional changes in skin tissues. This randomized, double-blind, placebocontrolled study in healthy adults tested the effect of Efamol evening primrose oil [EPO, a gamma-linolenic acid (GLA) containing vegetable oil] on skin moisture, transepidermal water loss (TEWL), redness, firmness, elasticity, fatigue resistance and roughness. Efamol EPO was administered orally in soft gel capsules, $3 \times 500 \mathrm{mg}$ b.i.d. for 12 weeks. Measurements were taken at baseline and at weeks 4 and 12 . The two treatment groups did not differ at baseline and at week 4 . At week 12, however, all measured variables, with the exception of skin redness, were significantly different in the EPO group compared with placebo. Skin moisture, TEWL, elasticity, firmness, fatigue resistance and roughness had significantly improved by $12.9,7.7,4.7,16.7,14.2$ and $21.7 \%$, respectively. The two-sided levels of significance in favor of the EPO treatment ranged between 0.034 and 0.001. These findings lend further support to the notion that GLA is a conditionally essential fatty acid for the skin, i.e. it is unable to synthesize GLA, and therefore depends on preformed GLA for optimal structure and function.

\section{Resume}

Les paramètres biophysiques cutanés sont des indicateurs des modifications structurelles et fonction-

Correspondence: Reto Muggli, AdviServ Consulting, Rotbergstrasse 11, CH-4114 Hofstetten, Switzerland. Tel.: +41 61 7312572; fax: +41 61 7312572; e-mail: reto.muggli@adviserv.ch nelles de la peau induites par l'âge. Cette étude randomisée, en double aveugle avec placebo, a permis d'évaluer les effets de l'EFAMOL huile d'Onagre (evening primrose oil ou EPO; une huile végétale contenant de l'acide gamma-linolénique ou AGL) sur l'hydratation, la perte d'eau trans-épidermique, la rougeur, la fermeté, l'élasticité, la résistance à la fatigue et la rugosité de la peau. L'EFAMOL EPO est administré oralement sous forme de capsules de gel souple à la dose de $3 \times 500 \mathrm{mg}$, deux fois par jour pendant 12 semaines. Les mesures sont faites au début du test et aux semaines 4 et 12 . Les deux groupes traités ne sont pas différents au départ et à la semaine 4. A la semaine 12 , cependant, toutes les variables mesurées, à l'exception de la rougeur cutanée, sont significativement différentes pour le groupe traité avec l'EPO comparé à celui traité avec le placebo. L'hydratation cutanée, la perte d'eau transépidermique, l'élasticité, la fermeté, la résistance à la fatigue et la rugosité sont respectivement améliorés de $12.9, \quad 7.7,4.7, \quad 16.7,14.2$ et $21.7 \%$. Les niveaux de significativité en faveur $\mathrm{du}$ traitement à l'EPO se situent entre 0.034 et 0.001. Ces résultats viennent conforter l'idée que l'AGL est un acide gras essentiel pour la peau qui, incapable de la synthétiser, en a néanmoins besoin pour optimiser sa structure et sa fonction.

\section{Introduction}

Evening primrose and borage oils have been reported to restore a defective epidermal skin barrier, to normalize excessive transepidermal water loss (TEWL) and to improve the smoothness of the skin both after topical application to healthy [1] and after systemic administration to eczematous adults 
[2]. The skin-improving effects have been ascribed to gamma-linolenic acid (GLA) of which evening primrose and borage oil are rich sources. These and other reports strongly suggest that skin may have an inherent requirement for GLA, and because the skin itself is unable to synthesize this fatty acid it relies on a supply of preformed GLA for optimal structure and function. This study tested the hypothesis that the skin smoothening and moistening effect seen after topical application of an evening primrose containing cream [2] could be reproduced by systematic application of EPO capsules to healthy volunteers. Various other biomechanical skin parameters were investigated in addition.

\section{Materials and methods}

The randomized, placebo-controlled, double-blind, parallel group trial was performed by Derma Consult GmbH, D-53347 Alfter, Germany.

\section{Subjects}

Twenty-two healthy non-pregnant females and 18 males between 32-56 years of age were recruited from the volunteer base of Derma Consult $\mathrm{GmbH}$, D-53347 Alfter, Germany. Both sexes were used in the study in order to make the study results representative for adults as a whole. All subjects were thoroughly informed of the purpose and the course of the study and that they could withdraw at any time without having to give a reason. Each volunteer had to give written informed consent and undergo an examination by a dermatologist prior to being entered into the study. Criteria for eligibility were: $\geq 18$ years old, clinically healthy, and self-assessed dry and rough skin. Any type of skin disease constituted an exclusion criterion.

The subjects were randomly allocated to either treatment group A or treatment group B. There was no significant difference between the age means of treatment group A (43.7 years) and B (44.2 years). Both groups consisted of 11 females and nine males. The subjects were instructed not to use any topical preparations on the test areas (inner sides of both forearms) starting from 7 days prior to until the end of the study. For cleansing, only water or a mild synthetic detergent (Eubos ${ }^{\circledR}$ Flüssig blau, Dr. Hobein GmbH, D-53340 Meckenheim, Germany) was allowed. Measurements were taken before treatment (day 0) and after treatment at days 28 and 84 . Before the measurements were taken, the subjects were adapted for $30 \mathrm{~min}$ to a room temperature of $21 \pm 1^{\circ} \mathrm{C}$ and a relative humidity of $50 \pm 5 \%$. The treatment comprised six $500 \mathrm{mg}$ capsules totalling for the active group $3 \mathrm{~g}$ Efamol EPO and providing $345 \mathrm{mg}$ GLA per day. The subjects were instructed to take three capsules twice daily in the morning and evening during meals.

\section{Materials}

Identically looking 500-mg soft gelatine capsules were manufactured for the evening primrose and the placebo group. Evening primrose oil (Rigel quality) was obtained from Efamol Ltd, Brackenholme, U.K. Medium-chain triglycerides [Miglyol $812 \mathrm{~N}$ (R), SYNOPHARM GmbH \& Co. KG, D-22885 Barsbüttel, Germany] served as placebo. Both oils were stabilized with $8 \mathrm{mg}$ of dl-alphatocopherol acetate. The GLA label claim per capsule was $57.5 \mathrm{mg}$.

\section{Measurements}

The following skin parameters were measured: moisture, redness, TEWL, elasticity, firmness, fatigue resistance and roughness.

\section{Skin moisture (corneometry)}

The skin moisture content was measured with the corneometer CM 825 PC (Courage + Khazaka electronic GmbH, D-50829 Cologne, Germany), which measures the electrical capacitance of the skin surface. The capacitance is expressed digitally in arbitrary units. The measuring principle [3] is based on the large difference of the dielectric constant of water (approximately 81) and that of most other materials (less than seven). The probe head $(7 \times 7 \mathrm{~mm})$ with the condenser was applied to the skin surface at a constant force of $3.5 \mathrm{~N}$. Three separate measurements on adjacent skin sites were performed, and the mean was used to define the hydration state of the stratum corneum.

\section{Transepidermal water loss}

Transepidermal water loss was measured with the Tewameter TM 210 (Courage + Khazaka electronic $\mathrm{GmbH}$ ). The Tewameter measures the water evaporation through the skin based on Fick's diffusion principle. The TEWL is calculated automatically and expressed digitally in $\mathrm{g} \mathrm{m}-2 \mathrm{~h}^{-1}$. The 
measurements were performed after the guidelines of the Standardization Group of the European Society of Contact Dermatitis [4]. Each value was the average of three different measurements on adjacent skin sites.

Skin redness (chromametry)

Skin color was measured with a Minolta Chromameter CR 300 (Minolta, Osaka, Japan) in compliance with the recommendations of the International Commission on Illumination (CIE), according to which the registration of color is adjusted to the non-linear color sensitivity of the human eye. Measurements were performed according to the guidelines of the Standardization Group of the European Society of Contact Dermatitis [5]. Three separate measurements were performed on adjacent skin sites, and the mean was used to define the degree of redness of the skin

Biomechanical skin properties (elasticity, firmness, fatigue resistance) (cutometry)

The biomechanical properties of the skin were assessed with the Cutometer SEM 575 (Courage + Khazaka electronic $\mathrm{GmbH})$. The measurement is based on the suction principle [6]. By applying a defined underpressure, skin is drawn into a hollow tube with an orifice of $2 \mathrm{~mm}$ in diameter. The skin is then allowed to retract at ambient pressure. The penetration depth of the skin into the tube is continuously recorded optically and frictionless as a function of time. A number of standardized parameters can be calculated from the penetration depth curve. To increase the accuracy and to obtain information on the properties of skin under repeated external stress, the suction-release cycle is repeated several times and the evaluation is based on area rather than point measurements (Fig. 1). Envelope curves fitting the equation $y=(\ln x+b) / a \quad(x=$ time, $y=$ maximum or minimum amplitude value) demarcate the areas. The study was conducted with 20 successive measurement cycles of $1 \mathrm{~s}$ suction (450 mbar) and $1 \mathrm{~s}$ retraction. Three area parameters were selected to assess the changes of three biomechanical skin properties: (1) skin firmness, defined by the area below the maximum envelope curve (F4). A decrease in $\mathrm{F} 4$ corresponds to an increase in skin firmness, (2) skin elasticity, defined by the ratio $\mathrm{F} 3 / \mathrm{F} 4$, where $\mathrm{F} 3$ is the area between the maximum and the minimum envelope curve. An increase in F3/F4 corresponds to an increase in the skin elasticity. The closer the ratio is to 1 , the more elastic is the skin, and (3) as a measure of viscoelasticity, skin fatigue, defined by $\mathrm{F} 2$, the area between the maximum envelope curve and the horizontal line through the calculated $y$-value at $x=40$ s. A decrease in F2 indicates an increase in fatigue resistance. The calculations were performed with the software WinCT (Courage + Khazaka electronic $\mathrm{GmbH}$ ).

\section{Skin roughness (profilometry)}

Skin roughness was measured with phase-shifting rapid in vivo measurement of skin (PRIMOS), a non-contact measurement device, which allows for real-time three-dimensional in vivo measurement
Figure 1 Measurement of biomechanical properties.

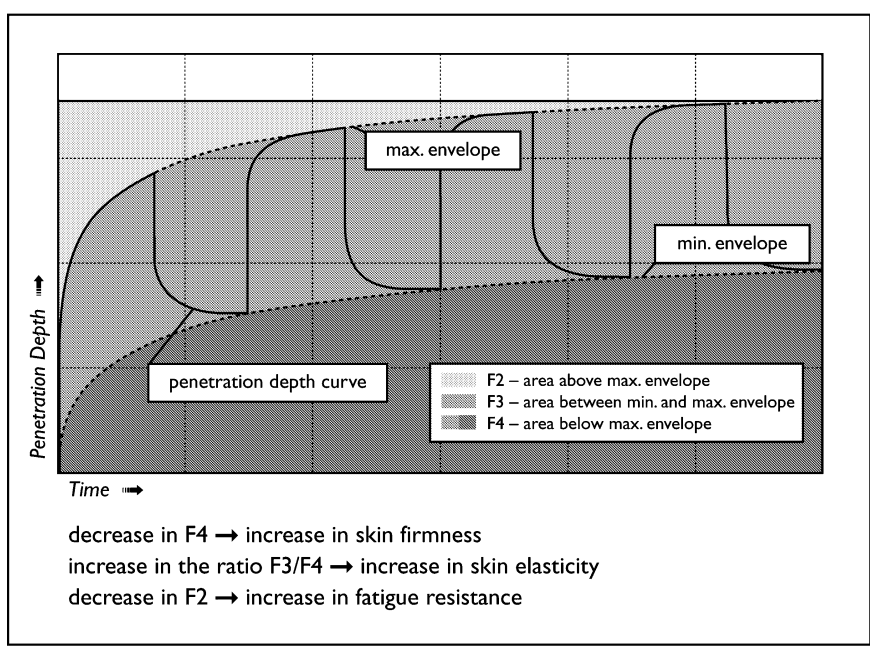


of the human skin microtopography based on active image triangulation [7]. To allow for the differences of human skin and to avoid undesired distortions by movements, the fast phase-shift technique was used for the measurement. Irregularities of the topography due to hairs were digitally removed by the PRIMOS software. Skin roughness was assessed by means of the parameter $R_{z}$ (mean depth of roughness) defined as

$$
R_{z}=\frac{1}{n} \sum_{i=1}^{n} R_{z i},
$$

where $n$ is the number of equal segments into which the scan length $l$ has been divided into and $R_{z i}$ is the maximum peak to valley depth within each individual segment. In accordance with the German Standard Din 4768/1, $R_{z}$ was calculated using five segments of equal length. To mitigate potential directional effects, the evaluation was conducted using the arithmetic average of $R_{z}$ from 32 different radial cuts.

\section{Biometry}

All measurements were automatically recorded, checked for validity and quality and stored centrally in a database. The data were evaluated with the software NAG ${ }^{\circledR}$ Statistical Add-Ins for Excel (The Numerical Algorithms Group Ltd, Oxford, U.K.). Because, the data may not necessarily be from a population of values that is Gaussian and because of the relatively small sample size the two treatment groups were compared with the Wilcoxon signed-rank test on differences. No correction for multiple variables was applied. Differences were considered significant at $P$-values $<0.05$ (two-sided).

\section{Results}

The supplements were well tolerated. Five women in the treatment and six women in the placebo group reported transient diarrhea-like symptoms in the beginning of the study. None of the volunteers withdrew from the study. The complete set of planned measurements could be obtained from all volunteers. The data are presented as group means in units as measured (Table I) and as percent change of the pretreatment value (Fig. 2).

The mean values of the two treatment groups at baseline did not differ significantly from each other and were very similar, with the exception of the roughness values. This indicates that the EPO and the placebo group were highly comparable with

Table I Effects of EPO on healthy skin $(n=20)$

\begin{tabular}{|c|c|c|c|c|}
\hline Parameter & Time of measurement & Placebo & EPO & Significance ${ }^{*}$ \\
\hline \multirow[t]{3}{*}{ Moisture } & Pretreatment & $36.2 \pm 6.2$ & $36.3 \pm 5.6$ & ns \\
\hline & 4 weeks & $40.2 \pm 6.4$ & $39.9 \pm 5.0$ & ns \\
\hline & 12 weeks & $36.5 \pm 5.6$ & $41.3 \pm 4.4$ & $P=0.012$ \\
\hline \multirow[t]{3}{*}{ TEWL } & Pretreatment & $9.1 \pm 1.1$ & $9.1 \pm 1.0$ & ns \\
\hline & 4 weeks & $9.1 \pm 1.1$ & $8.9 \pm 1.3$ & ns \\
\hline & 12 weeks & $9.1 \pm 0.8$ & $8.4 \pm 1.0$ & $P=0.034$ \\
\hline \multirow[t]{3}{*}{ Redness } & Pretreatment & $7.9 \pm 1.4$ & $8.6 \pm 1.1$ & $\mathrm{~ns}$ \\
\hline & 4 weeks & $7.9 \pm 1.0$ & $8.3 \pm 1.3$ & ns \\
\hline & 12 weeks & $7.9 \pm 1.6$ & $8.6 \pm 1.1$ & ns \\
\hline \multirow[t]{3}{*}{ Elasticity } & Pretreatment & $0.86 \pm 0.11$ & $0.86 \pm 0.11$ & ns \\
\hline & 4 weeks & $0.86 \pm 0.09$ & $0.88 \pm 0.08$ & ns \\
\hline & 12 weeks & $0.86 \pm 0.06$ & $0.90 \pm 0.08$ & $P=0.002$ \\
\hline \multirow[t]{3}{*}{ Firmness } & Pretreatment & $1493 \pm 328$ & $1513 \pm 248$ & ns \\
\hline & 4 weeks & $1453 \pm 167$ & $1370 \pm 225$ & ns \\
\hline & 12 weeks & $1457 \pm 199$ & $1231 \pm 189$ & $P=0.001$ \\
\hline \multirow[t]{3}{*}{ Fatigue resistance } & Pretreatment & $106 \pm 14$ & $108 \pm 18$ & ns \\
\hline & 4 weeks & $104 \pm 17$ & $106 \pm 18$ & ns \\
\hline & 12 weeks & $107 \pm 15$ & $93 \pm 15$ & $P=0.036$ \\
\hline \multirow[t]{3}{*}{ Roughness } & Pretreatment & $177 \pm 26$ & $191 \pm 23$ & ns \\
\hline & 4 weeks & $185 \pm 30$ & $190 \pm 25$ & ns \\
\hline & 12 weeks & $183 \pm 33$ & $154 \pm 31$ & $P=0.040$ \\
\hline
\end{tabular}

Means $\pm S D$, "Wilcoxon signed-rank test on differences between EPO and placebo. 


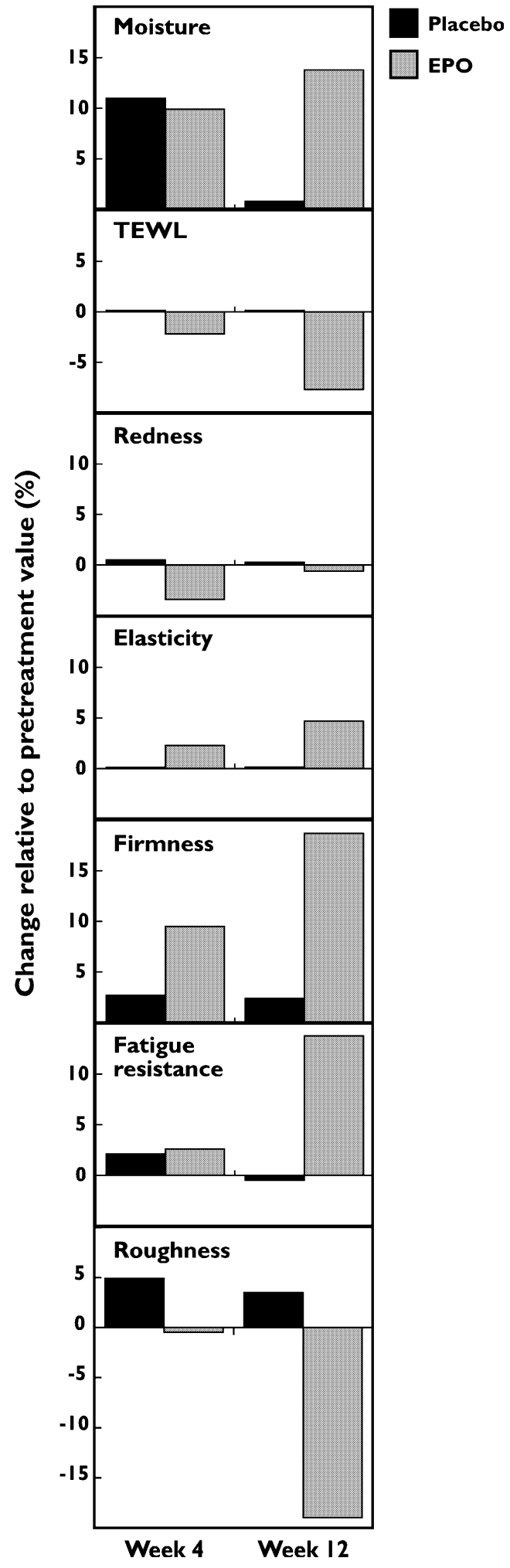

Figure 2 Effects of EPO on healthy skin $(n=20)$. respect to their skin properties. None of the mean values of the placebo group at week 4 and 12 differed significantly from the pretreatment value. The values after EPO treatment at week 4 did not differ significantly from either the corresponding baseline values or from those of the placebo group. The picture was different 8 weeks later. At week 12 , the values of all skin parameters were significantly better in the EPO group compared with the placebo group, with the exception of skin redness. Significant improvements in terms of per cent difference to the placebo were measured: moisture, 12.9\%; TEWL, 7.7\%; elasticity, 4.7\%; firmness, $16.7 \%$; fatigue resistance $14.2 \%$; and roughness, $21.7 \%$. The levels of statistical significances ranged between $P=0.034$ and 0.001 .

\section{Discussion and conclusions}

Lipids are integral components of the skin and of these the omega- 6 fatty acid linoleic acid (LA), recognized to be an essential nutrient, is known to play a crucial role in skin physiology. Low intakes of LA lead to scaling and thickening of the epidermis, accompanied by an increased loss of water across the epidermis. The latter is a cardinal sign of a disturbed epidermal skin barrier and the lead symptom in essential fatty acid deficiency. Linoleic acid, applied systemically or topically, has been shown to regenerate a defective skin barrier in animals and humans deficient in essential fatty acids [8].

The mechanism by which LA maintains skin integrity and function is only incompletely understood. Linoleic acid is the prominent fatty acid in ceramides, the largest polar lipid class of the stratum corneum. Linoleic acid deficiency leads to disruption of the stacked lipid bilayers surrounding the corneocytes of the horny layer resulting in a breakdown of the barrier function [9]. Apart from this structural function, LA has a metabolic role as the parent fatty acid of the long-chain polyunsaturated fatty acid GLA (C18:3n-6). Gamma-linolenic acid itself is rapidly and efficiently transformed to dihomo-gamma-linolenic acid (DGLA), the precursor of prostaglandin E1 and 15-hydroxy-eicosatrienoic acid [10], metabolites which have potent anti-inflammatory effects. Furthermore, GLA suppresses, at least in vitro, the formation or release of IL-1 $\beta$ and TNF- $\alpha$, both important inflammatory mediators [11-13]. Consequently, a deficiency in LA and by implica- 
tion that of GLA may not only disrupt the skin barrier but also may predispose the skin to inflammatory overreactions, i.e. the skin reacts already to minor insults with an overshooting or chronic inflammatory response.

Despite the fact that LA deficiency is virtually non-existent in industrialized societies where, on the contrary, the diet is characterized by a relative oversupply of LA because of the widespread use of vegetable oils in the diet, the skin may still be undersupplied with GLA. Gamma-linolenic acid is metabolized from its precursor LA, provided that the delta-6-desaturase, the transforming enzyme, is functional and present in sufficient amounts. The delta-6-desaturase can be impaired genetically, by age and metabolic diseases (diabetes) $[14,15]$. Nutrition may also affect the activity of the enzyme as it has been shown that excessive intakes of saturated fatty acids, trans fatty acids, suboptimal intakes of zinc, magnesium, and vitamin B6 as well as smoking, alcohol and psychological stress may lower the activity of the enzyme $[14,16]$. Thus, insufficient amounts of GLA may be produced by the body even in the presence of adequate LA. The skin is particularly sensitive to suboptimal GLA supply as it lacks the necessary delta-6-desaturase enzyme with which to form it in situ. This could have profound effects on skin barrier function and on dermal immuno-inflammation. In fact, there is some evidence that the inflammatory component of eczema, psoriasis and other skin affections might be the result of inadequate amounts of prostaglandin E1 and 15-hydroxy-eicosatrienoic acid due to the lack of the substrate GLA [10]. Obviously, the skin is an organ that seems to depend on the supply of preformed GLA.

If a restricted metabolism of LA to GLA weakens the skin barrier and shifts the eicosanoid metabolism toward a higher inflammation status, substitution therapy with GLA should produce relief. Indeed, several animal and clinical studies have shown this to be the case. Oral administration of GLA to guinea pigs and rats leads to higher levels of this fatty acid in the structural lipids of the epidermis and to an increase of the anti-inflammatory mediators prostaglandin E1 and 15-hydroxy-eicosatrienoic acid in the epidermis [17-21]. In animal models, injury to the skin barrier - manifested by an increased TEWL - and other skin changes as the result of a fatty acid deficient diet or from application of a lipid disrupting detergent could be reversed by oral treatment with GLA-rich vegetable oils [11,17,19,21-23].

Clinical studies corroborated the findings in animals. The regular intake of GLA-rich vegetable oils has been reported to normalize the balance of inflammatory eicosanoids and to mitigate the symptoms of chronic inflammatory disorders such as rheumatoid arthritis and atopic eczema [24,25]. Topically or systemically applied evening primrose or borage oil helped restore the natural epidermal barrier function or accelerated its recovery when it had been previously injured [1,2,26]. Transepidermal water loss was lowered, skin moisture increased and the skin attained a smoother appearance.

The present study indicates that the regular intake of EPO, oil with a high GLA content, strengthens the physiological skin barrier function, improves the biomechanical properties and smoothes the surface profile of skin. Lending credence to the findings was the observation that it took longer than 4 weeks supplementation for the effects to show. This is in line with the fact that it takes at least 4 weeks for middle-aged epidermis to turn over and for fatty acids to reach a new steady-state tissue concentration. Even though the exact mechanism of activity is unknown, this study supports the notion that GLA is a conditionally essential fatty acid for skin - i.e. it can be manufactured from LA by the body, but only at low and potentially insufficient rate - and that it may have a role in skin care.

\section{References}

1. Nissen, H.P., Biltz, H. and Muggli, R. Borage oil. Gamma-linolenic acid decreases skin roughness and TEWL and increases skin moisture in normal and irritated human skin. Cosmetics \& Toiletries 110 , 71-74 (1995).

2. Nissen, H.P., Wehrmann, W., Kroll, U. and Kreysel, H.W. Influence of polyunsaturated fatty acids on the plasma phospholipids of atopic patients. Fat Sci. Technol. 7, 268-271 (1988).

3. Bettinger, J., Gloor, M., Vollert, A. et al. Comparison of different non-invasive test methods with respect to the effect of different moisturizers on skin. Skin Res. Technol. 5, 21-27 (1999).

4. Pinnagoda, J., Tupker, R.A., Agner, T. and Serup, J. Guidelines for transepidermal water loss (TEWL) measurement. A report from the Standardization Group of the European Society of Contact Dermatitis. Contact Dermatitis 22, 164-178 (1990). 
5. Fullerton, A., Fischer, T., Lahti, A. et al. Guidelines for measurement of skin colour and erythema. A report from the Standardization Group of the European Society of Contact Dermatitis. Contact Dermatitis 35, 1-10 (1996).

6. Barel, A.O., Courage, W. and Clarys, P. Suction method for measurement of skin mechanical properties: the cutometer. In: Handbook of non-invasive methods and the skin (Serup, J. and Jemec, G.B.E. eds.), pp. 335-340. CRC Press, Ann Arbor (1995).

7. Jaspers, S., Hopermann, H., Sauermann, G. et al. Rapid in vivo measurement of the topography of human skin by active image triangulation using a digital micromirror device. Skin Res. Technol. 5, 195-207 (1999).

8. Hansen, H.S. and Jensen, B. Essential function of linoleic acid esterified in acylglucosylceramide and acylceramide in maintaining the epidermal water permeability barrier. Evidence from feeding studies with oleate, linoleate, arachidonate, columbinate and alpha-linolenate. Biochim. Biophys. Acta $\mathbf{8 3 4}$, 357-363 (1985).

9. Wertz, P.W., Swartzendruber, D.C., Abraham, W., Madison, K.C. and Downing, D.T. Essential fatty acids and epidermal integrity. Arch. Dermatol. 123, 1381-1384 (1987).

10. Ziboh, V.A., Miller, C.C. and Cho, Y. Metabolism of polyunsaturated fatty acids by skin epidermal enzymes: generation of antiinflammatory and antiproliferative metabolites. Am. J. Clin. Nutr. 71 (Suppl.), 361S-366S (2000).

11. DeLuca, P., Rossetti, R.G., Alavian, C., Karim, P. and Zurier, R.B. Effects of gammalinolenic acid on interleukin- $1 \beta$ and tumor necrosis factor- $\alpha$ secretion by stimulated human peripheral blood monocytes: studies in vitro and in vivo. J. Investig. Med. 47, 246250 (1999).

12. Furse, R.K., Rossetti, R.G., Seiler, C.M. and Zurier, R.B. Oral administration of gammalinolenic acid, an unsaturated fatty acid with anti-inflammatory properties, modulates interleukin-1 $\beta$ production by human monocytes. J. Clin. Immunol. 22, 83-91 (2002).

13. Dooper, M.M.B.W., van Riel, B., Graus, Y.M.F. and M'Rabet, L. Dihomo- $\gamma$-linolenic acid inhibits tumour necrosis factor- $\alpha$ production by human leucocytes independently of cyclooxygenase activity. Immunol. 110, 348-357 (2003).

14. Horrobin, D.F. Gamma-linolenic acid: an intermediate in essential fatty acid metabolism with potential as an ethical pharmaceutical and as a food. Rev. Contemp. Pharmacother. 1, 1-45 (1990).
15. Jones, D.B., Carter, R.D. and Mann, J.I. Indirect evidence of impairment of platelet desaturase enzymes in diabetes mellitus. Horm. Metab. Res. 18, 341-344 (1986).

16. Leng, G.C., Smith, F.B., Fowkes, F.G. et al. Relationship between plasma essential fatty acids and smoking, serum lipids, blood pressure and haemostatic and rheological factors. Prostaglandins Leukot. Essent. Fatty Acids 51, 101-108 (1994).

17. Chapkin, R.S., Ziboh, V.A. and McCullough, J.L. Dietary influences of evening primrose and fish oil on the skin of essential fatty acid-deficient guinea pigs. J. Nutr. 117, 1360-1370 (1987).

18. Miller, C.C., Tang, W., Ziboh, V.A. and Fletcher, M.P. Dietary supplementation with ethyl ester concentrates of fish oil (n-3) and borage oil (n-6) polyunsaturated fatty acids induces epidermal generation of local putative anti-inflammatory metabolites. J. Invest. Dermatol. 96, 98-103 (1991).

19. Hartop, P.J. and Prottey, C. Changes in transepidermal water loss and the composition of epidermal lecithin after applications of pure fatty acid triglycerides to skin of essential fatty acid-deficient rats. Br. J. Dermatol. 95, 255-264 (1976).

20. Miller, C.C. and Ziboh, V.A. Gammalinolenic acidenriched diet alters cutaneous eicosanoids. Biochem. Biophys. Res. Commun. 154, 967-974 (1988).

21. Chung, S., Kong, S., Seong, K. and Cho, Y. $\gamma$-linolenic acid in borage oil reverses epidermal hyperproliferation in guinea pigs. J. Nutr. 132, 3090-3097 (2002).

22. Ziboh, V.A. and Chapkin, R.S. Biologic significance of polyunsaturated fatty acids in the skin. Arch. Dermatol. 123, 1686a-1690a (1987).

23. Prottey, C., Hartop, P.J., Black, J.G. and McCormack, J.I. The repair of impaired epidermal barrier function in rats by the cutaneous application of linoleic acid. Br. J. Dermatol. 94, 13-21 (1976).

24. Belch, J.J.F. and Hill, A. Evening primrose oil and borage oil in rheumatologic conditions. Am. J. Clin. Nutr. 71 (Suppl.), 352S-356S (2000).

25. Horrobin, D.F. Essential fatty acid metabolism and its modification in atopic eczema. Am. J. Clin. Nutr. 71 (Suppl.), 367S-372S (2000).

26. Gehring, W., Bopp, R., Rippke, F. and Gloor, M. Effect of topically applied evening primrose oil on epidermal barrier function in atopic dermatitis as a function of vehicle. Arzneimittelforschung. 49, 635642 (1999). 